Article

\title{
Factors Associated with Having Family/Whānau or Close Friends Who Used Alcohol or Other Drugs in Harmful Ways among University Students in New Zealand
}

\author{
Ben Wamamili $^{1, *(\mathbb{D})}$, Pauline Stewart ${ }^{2}$ and Mark Wallace-Bell ${ }^{1}$ \\ 1 School of Health Sciences, University of Canterbury, Christchurch 8041, New Zealand; \\ mark.wallace-bell@canterbury.ac.nz \\ 2 Family Drug Support Aotearoa, Christchurch 8011, New Zealand; paulinestewartphd@gmail.com \\ * Correspondence: ben.wamamili@canterbury.ac.nz
}

check for updates

Citation: Wamamili, B.; Stewart, P.; Wallace-Bell, M. Factors Associated with Having Family/Whānau or Close Friends Who Used Alcohol or Other Drugs in Harmful Ways among University Students in New Zealand. Int. J. Environ. Res. Public Health 2022, 19, 243. https://doi.org/ 10.3390/ijerph19010243

Academic Editor: Carol Cunradi

Received: 25 October 2021

Accepted: 23 December 2021

Published: 26 December 2021

Publisher's Note: MDPI stays neutral with regard to jurisdictional claims in published maps and institutional affiliations.

Copyright: (C) 2021 by the authors. Licensee MDPI, Basel, Switzerland. This article is an open access article distributed under the terms and conditions of the Creative Commons Attribution (CC BY) license (https:// creativecommons.org/licenses/by/ $4.0 /)$.

\begin{abstract}
The consequences of alcohol and other drug (AoD) use are well documented. This study investigated factors associated with having family/whānau or close friend who used AoD in harmful ways in New Zealand. Data came from a July-August 2020 cross-sectional survey of students from eight universities $(n=946)$. Participants were asked if they had family/whānau or close friends in New Zealand who consumed alcohol or used other drugs (cannabis, ecstasy/MDMA, methamphetamine, cocaine, heroin, prescription drugs, inhalants, or other) in a way that negatively impacted them, their family, or close friends in the last 12 months. Logistic regression assessed associations of having family/whānau or close friend who used AoD harmfully with student characteristics. Of respondents, 36.2\% (33.1-39.4) had family/whānau or close friend who had consumed alcohol harmfully, and 42.9\% (39.5-46.3) had family/whānau or close friend who had used at least one drug harmfully. Respondents' age and ethnicity were significantly associated with having family/whānau or close friend who used AoD harmfully. The results suggest widespread harmful AoD use and potentially significant second-hand effects of AoD use in New Zealand. These data can be used to supplement information from traditional in-person surveys of individuals using alcohol and other drug (e.g., the New Zealand Health Survey).
\end{abstract}

Keywords: alcohol use; AoD use; other drug use; family/whanau; close friend

\section{Introduction}

The negative consequences of alcohol and other drug use (legal and illicit) (AoD) on the health, economic, and social aspects of individuals and communities are well documented [1,2]. Alcohol is one of the most widely used substances globally and is part of many cultural, religious, and social practices [3]. Data from the New Zealand Health Survey (NZHS) show that in 2020/21, four in five (78.5\%) adults aged $15+$ years consumed an alcoholic drink and one in five (19.9\%) engaged in hazardous drinking (defined as an established pattern of drinking that carries a high risk of damage to physical or mental health) [4]. The prevalence of hazardous drinking was highest in adults aged 18-24 (32.9\%). Men were 2.0 times more likely than women, and Māori (the Indigenous population of New Zealand) were 1.7 times more likely than non-Māori to be hazardous drinkers. The NZHS provides limited data on illicit drug use. However, it reports that $15.3 \%$ and $1.0 \%$ of adults used cannabis and amphetamine, respectively, in the past year and men were more likely than women, and Māori more likely than non-Māori to have used these drugs [4]. A 2017 report on the global statistics on alcohol, tobacco, and illicit drug use suggests that New Zealand has some of the highest age-standardised rates of amphetamine, cannabis, opioid, and cocaine use dependence in Australasia [5].

The harmful effects of AoD [6-9] are far reaching, impacting on the user, their loved ones, and communities [10]. A 2011 study of New Zealanders aged 12-80 years $(n=3068)$ found that $24.8 \%$ had at least one self-defined heavy drinker in their life, $84 \%$ of whom 
experienced at least one harm (physical, social, economic or psychological) related to the person's drinking [11]. A second study found people who had moderate-to-high exposure to heavy drinkers (particularly close household contacts) were 2.3-2.8 times more likely than people with no heavy drinkers in their lives to experience lower health status and personal wellbeing, such as decreased 'usual' activity; significant pain and discomfort, and anxiety and depression [12]. Another study of New Zealand adults aged 18-70 years ( $n=1925)$ found that $15 \%$ of men and $12 \%$ of women reported experiencing an aggressive act by a partner, and $11 \%$ of men and $16 \%$ of women reported being aggressive towards a partner in the past two years. Alcohol was involved in more than $25 \%$ of incidents [13].

In New Zealand, the Government's approach to AoD use is set out in the National Drug Policy, which guides policy and practices aimed at preventing and reducing AoDrelated harm in the community $[10,14]$. The current policy emphasises the need for a person-centred intervention and responses to AoD use that reflect the individual drug's risk profile [10]. The goals of the policy range from total eradication of use and supply (e.g., methamphetamine) to harm minimisation (e.g., alcohol).

The available literature on AoD use is focused on risk factors from an individual user's level and peers are among the most important risk factors in the development of AoD use in adolescents and young adults [15]. Peers model AoD use behaviours and increase the positive expectancies of AoD use. Experimentation with AoD during adolescence (high school students) and early adulthood (college and university students) often occurs in a social setting [16]. Commencement of university coincides with a period (16-25 years) at which substance use disorders are at their peak in young people [17]. For most students, AoD use provides a forum for meeting new friends, socialising, and peer relationships [18].

Previous studies have described the prevalence and impact of AoD use on university (and college) students in New Zealand (hazardous drinking ranged from 68\% to $70 \%$ ) $[19,20]$ and elsewhere [21-23]. Poor academic performance; unintentional injuries; physical assault; sexual assault; unsafe sex; memory loss, and property damage are common in students who use AoD [24,25]. These effects are not limited to students who use AoD. Students who abstain from AoD use may experience second-hand effects, including disrupted study time or sleep due to babysitting intoxicated peers or emotional distress from insults or humiliation because of a peer's AoD use. [26] Data on the prevalence and impacts of AoD use among university students' family/whānau members or close friends are lacking. The current exploratory study examined the associations between student characteristics (age, gender, and ethnicity) with having family members or close friends who used AoD in a harmful way in the last 12 months. This approach provides novel data by shifting the focus from the individual user to their wider social sphere.

\section{Materials and Methods}

\subsection{Design and Data Source}

Data were obtained from a cross-section of students across New Zealand between 21 July and 18 August 2020. All students enrolled at any of the eight universities (University of Auckland, Auckland University of Technology, University of Canterbury, Lincoln University, Massey University, University of Otago, University of Waikato, or Victoria University of Wellington) were eligible to participate. A convenience sample was used because complete enrolment lists of students were not available from the universities to allow for random sampling. The survey was, however, widely advertised on social media platforms popular with students, including student associations' Facebook pages, and could be completed anonymously online or on paper.

Paper questionnaires were distributed by research assistants who were recruited from students at respective universities through Student Job Search [27]. The research assistants were trained to approach students on campus (at cafes, outside libraries and lecture halls) and invite them to complete the survey on paper or online by scanning a QR code using a smartphone. Research assistants were not allowed to complete the questionnaire on behalf of participants, but rather instructed to distribute questionnaires and pens and collect the 
completed questionnaires when participants indicated they were finished. Participants were required to be aged 18 years or older and able to consent before participating. A total of 946 students participated (171 online, 775 on paper).

All procedures were performed in compliance with the University of Canterbury Human Ethics Committee (HEC 2020/35) which reviewed and approved this research.

\subsection{Measures}

\subsubsection{Demographic Characteristics}

Participants were asked their age, which was categorised as 18-24 years, 25-34 years and 35 years or older. Gender was categorised as male, female, and other (includes 'other'; 'prefer not to say' and missing data), and ethnicity was categorised as New Zealand European, Māori, Pasifika, Asian, and Other. Pasifika includes Samoan, Cook Island Māori, Tongan and Niuean, while Asian includes Indian and Chinese.

\subsubsection{Alcohol Use}

Participants were asked, "Do you have a family member or close friend who you feel drinks alcohol excessively or has in the last 12 months? By this, we mean that their drinking has negatively impacted them, their family or their close friends." The responses included "Yes", "No", "Don't know" (no responses were obtained for this option), and "Would rather not say".

\subsubsection{Drug Use}

Participants were asked, "Do you have a family member or close friend who in the last 12 months has used any of the following drugs in a way which has negatively impacted them, their family or their close friends?" The responses included "Cannabis", "Synthetic cannabis", "Ecstasy or MDMA", "Methamphetamine (Meth, P)", "Cocaine", "Heroin", "Prescription drugs", "Inhalants (e.g., sniffing glue, lighter fluid, solvents)", "Other", "Don't know", "No, I do not have a family member or close friend who has used any of the above", and "Would rather not say".

\subsection{Statistical Analysis}

Descriptive statistics were conducted to assess the overall rates of exposure to harmful AoD use among family/whānau or close friend. Binary logistic regression analysis examined the relationship between age, gender, and ethnicity and having family/whānau or close friends who consumed alcohol harmfully, or used at least one of three most reported drugs (i.e., cannabis, ecstasy or MDMA, and prescription drugs) harmfully.

Age was coded as $(1=35$ or older; $2=25-34$, and $3=18-24)$ and gender as $(1=$ other, 2 = female, and 3 = male). Ethnicity $(1=$ NZ European, Māori, Pasifika, Asian or Other, and 2 = non-NZ European, non-Māori, non-Pasifika, non-Asian or non-Other). Although participants could select more than one ethnicity, a binary variable was necessary for the purpose of analysis. For this reason, each ethnic group was compared with all other four groups combined (i.e., NZ European vs. non-NZ European). Harmful consumption of alcohol was coded as ( 1 = yes, $2=$ no), and harmful use of drugs (cannabis, ecstasy or MDMA, or prescription drugs) as $(1=$ yes, $2=$ no). All statistical analyses were performed using IBM SPSS Statistics V.27 and two-sided $p<0.05$ was considered statistically significant. Adjusted odds ratios (AOR) with the associated confidence intervals $(95 \% \mathrm{CI})$ were reported.

\section{Results}

\subsection{Participants}

The analysis included 946 students. The demographic characteristics of participants are displayed in Table 1. 
Table 1. Demographic characteristics of participants.

\begin{tabular}{cc}
\hline & $(\boldsymbol{n}=\mathbf{9 4 6}), \boldsymbol{\%}$ \\
\hline Age (years) & $751(79.4)$ \\
$18-24$ & $152(16.1)$ \\
$25-34$ & $43(4.5)$ \\
35 or older & \\
Gender & $371(39.2)$ \\
Male & $555(58.7)$ \\
Female & $20(2.1)$ \\
Other & \\
Ethnicity * & $469(49.6)$ \\
New Zealand European & $80(8.5)$ \\
Māori & $110(11.6)$ \\
Pasifika & $186(19.7)$ \\
Asian & $228(24.1)$ \\
Other & \\
Survey type & $171(18.1)$ \\
Online & $775(81.9)$ \\
Paper &
\end{tabular}

* Total may exceed $100 \%$ because respondents could choose multiple responses.

\subsection{Alcohol Use}

A total of 873 complete responses ( $92.3 \%$ of the sample) (159 online and 714 on paper) were reported. Overall, $36.2 \%$ (95\% CI: 33.1 to 39.4) had family/whānau members or close friends who had consumed alcohol in a harmful way in the last 12 months, $62.0 \%$ did not, and $1.8 \%$ would rather not say. There were no significant differences in responses based on survey type $(p=0.127)$ (Table 2$)$.

Table 2. Respondents who had family/whānau member or close friend who consumed alcohol in a harmful way, by questionnaire type.

\begin{tabular}{ccccc}
\hline & $\begin{array}{c}\text { Online }(\boldsymbol{n}=\mathbf{1 5 9}) \\
\mathbf{\%}(\mathbf{9 5} \% \mathbf{C I})\end{array}$ & $\begin{array}{c}\text { Paper }(\boldsymbol{n = 7 1 4 )} \\
\mathbf{\%}(\mathbf{9 5} \% \mathbf{C I})\end{array}$ & $\begin{array}{c}\text { Total }(\boldsymbol{n}=\mathbf{8 7 3}) \\
\mathbf{\%} \mathbf{( 9 5 \% ~ C I )}\end{array}$ & $p$-Value \\
\hline Yes & $40.9(33.5-48.7)$ & $35.2(31.7-38.7)$ & $36.2(33.1-39.4)$ & \\
No & $56.0(48.2-63.5)$ & $63.3(59.7-66.8)$ & $62.0(58.7-65.1)$ & 0.127 \\
Would rather not say & $3.1(1.4-7.2)$ & $1.5(0.9-2.7)$ & $1.8(1.1-3.0)$ & \\
\hline
\end{tabular}

3.3. The Association between Having Family/Whānau or Close Friend Who Consumed Alcohol in a Harmful Way, with Age, Gender, and Ethnicity

A set of binary logistic models predicted the likelihood of having family/whānau or close friend who consumed alcohol in a harmful way (outcome) with age group, gender, and ethnicity (predictors). The overall model was significant, $\chi^{2}(\mathrm{df}=9, n=857)=55.097$, $p<0.001$. Only ethnicity made a significant contribution to the model (Table 3). Māori had significantly higher odds of having family/whānau member or close friend who consumed alcohol in a harmful way compared with non-Māori (AOR $=2.50,95 \%$ CI: 1.50 to 4.18 ). 
Table 3. Binary logistic models predicting the likelihood of having family/whānau or close friend who consumed alcohol in a harmful way.

\begin{tabular}{|c|c|c|c|c|c|c|}
\hline & & & B & AOR & $95 \%$ CI & $p$-Value \\
\hline \multirow{3}{*}{$\begin{array}{l}\text { Alcohol use vs. } \\
\text { No alcohol use }\end{array}$} & Age & $\begin{array}{l}18-24 \text { years } \\
25-34 \text { years } \\
35 \text { or older }\end{array}$ & $\begin{array}{c}\text { Ref } \\
0.17 \\
-0.08\end{array}$ & $\begin{array}{l}1.18 \\
0.92\end{array}$ & $\begin{array}{l}0.77-1.81 \\
0.47-1.82\end{array}$ & $\begin{array}{l}0.445 \\
0.818\end{array}$ \\
\hline & Gender & $\begin{array}{c}\text { Male } \\
\text { Female } \\
\text { Other }\end{array}$ & $\begin{array}{c}\text { Ref } \\
-0.14 \\
0.17 \\
\end{array}$ & $\begin{array}{l}0.87 \\
1.18\end{array}$ & $\begin{array}{l}0.65-1.18 \\
0.42-3.37 \\
\end{array}$ & $\begin{array}{l}0.368 \\
0.753\end{array}$ \\
\hline & Ethnicity & $\begin{array}{c}\text { NZ European } \\
\text { Maori } \\
\text { Pasifika } \\
\text { Asian } \\
\text { Other }\end{array}$ & $\begin{array}{c}0.50 \\
0.92 \\
0.36 \\
-0.43 \\
-0.30\end{array}$ & $\begin{array}{l}1.65 \\
2.50 \\
1.44 \\
0.65 \\
0.74\end{array}$ & $\begin{array}{l}0.98-2.77 \\
1.50-4.18 \\
0.80-2.58 \\
0.37-1.16 \\
0.43-1.29\end{array}$ & $\begin{array}{c}0.062 \\
<0.001 \\
0.227 \\
0.147 \\
0.286\end{array}$ \\
\hline
\end{tabular}

\subsection{Other Drug Use}

A total of 798 complete responses (84.4\% of the sample) were reported. Overall, $42.9 \%$ (95\% CI: 39.5 to 46.3) reported a family/whānau member or close friend who used at least one drug in a harmful way in the last 12 months. Cannabis (32.7\%), ecstasy or MDMA $(25.2 \%)$, and prescription drugs $(10.5 \%)$ were the three most reported drugs (Table 4$)$.

Table 4. Respondents who had family/whānau member or close friend who used drugs in a harmful way.

\begin{tabular}{cccc}
\hline & $(\boldsymbol{n = 7 9 8 )}$ & $\mathbf{\%}$ & $\mathbf{9 5 \%} \mathbf{C I}$ \\
\hline At least one drug including 'other' & 342 & 42.9 & $39.5-46.3$ \\
\hline Cannabis & 261 & 32.7 & $29.5-36.0$ \\
\hline Synthetic cannabis & 39 & 4.9 & $3.6-6.6$ \\
\hline Ecstasy or MDMA & 201 & 25.2 & $22.3-28.3$ \\
\hline Methamphetamine (Meth, P) & 49 & 6.1 & $4.7-8.0$ \\
\hline Cocaine & 44 & 5.5 & $4.1-7.3$ \\
\hline Heroin & 15 & 1.9 & $1.1-3.1$ \\
\hline $\begin{array}{c}\text { Inhalants (e.g., sniffing glue, lighter fluid, } \\
\text { solvents, etc.) }\end{array}$ & 84 & 10.5 & $8.6-12.9$ \\
\hline Other & 33 & 4.1 & $3.0-5.8$ \\
\hline $\begin{array}{c}\text { No, I do not have a family member or close } \\
\text { friend who used any of the above }\end{array}$ & 439 & 5.4 & $4.0-7.2$ \\
\hline Would rather not say & 17 & 55.0 & $5.6-58.4$ \\
\hline
\end{tabular}

3.5. The Association between Having Family/Whānau or Close Friend Who Used Drugs (Cannabis, Ecstasy or mdma, or Prescription Drugs) in a Harmful Way with Age, Gender, and Ethnicity

\subsubsection{Cannabis}

The overall model was significant, $\chi^{2}(\mathrm{df}=9, n=798)=96.049, p<0.001$; age and ethnicity made a significant contribution to the model (Table 5). Respondents who were aged 25-34 had higher odds than respondents aged 18-24 of having family/whānau or close friend who used cannabis in a harmful way (AOR $=2.08,95 \% \mathrm{CI}: 1.23$ to 3.52). NZ European $(\mathrm{AOR}=4.26,95 \% \mathrm{CI}: 2.48$ to 7.32), and Māori (AOR = 4.53, 95\% CI: 2.55 to 8.06) had similar odds compared with non-NZ European and non-Māori, respectively. Likewise, Pasifika (AOR = 2.06, 95\% CI: 1.08 to 3.92) and Other (AOR = 2.27, 95\% CI: 1.29 to 
4.00) had similar odds compared with non-Pasifika and non-Other, respectively, of having family/whānau member or close friend who used cannabis in a harmful way.

Table 5. Binary logistic models predicting the likelihood of having family/whānau or close friend who used cannabis, ecstasy/MDMA or prescription drugs in a harmful way.

\begin{tabular}{|c|c|c|c|c|c|c|}
\hline & & & B & AOR & $95 \%$ CI & $p$-Value \\
\hline \multirow{11}{*}{$\begin{array}{l}\text { Cannabis use vs. No } \\
\text { cannabis use }\end{array}$} & \multirow{3}{*}{ Age } & 18-24 years & Ref & & & \\
\hline & & $25-34$ years & 0.73 & 2.08 & $1.23-3.52$ & 0.006 \\
\hline & & 35 or older & 0.61 & 1.83 & $0.80-4.18$ & 0.150 \\
\hline & \multirow{3}{*}{ Gender } & Male & Ref & & & \\
\hline & & Female & 0.02 & 1.02 & $0.74-1.42$ & 0.889 \\
\hline & & Other & 0.20 & 1.22 & $0.42-3.55$ & 0.711 \\
\hline & \multirow{5}{*}{ Ethnicity } & NZ European & 1.45 & 4.26 & $2.48-7.32$ & $<0.001$ \\
\hline & & Maori & 1.51 & 4.53 & $2.55-8.06$ & $<0.001$ \\
\hline & & Pasifika & 0.72 & 2.06 & $1.08-3.92$ & 0.028 \\
\hline & & Asian & 0.17 & 1.18 & $0.64-2.19$ & 0.591 \\
\hline & & Other & 0.82 & 2.27 & $1.29-4.00$ & 0.005 \\
\hline \multirow{11}{*}{$\begin{array}{l}\text { Ecstasy/MDMA use vs. } \\
\text { No ecstasy/MDMA use }\end{array}$} & \multirow{3}{*}{ Age } & 18-24 years & Ref & & & \\
\hline & & $25-34$ years & 1.06 & 2.88 & $1.53-5.43$ & 0.001 \\
\hline & & 35 or older & 1.03 & 2.81 & $0.96-8.22$ & 0.060 \\
\hline & \multirow{3}{*}{ Gender } & Male & Ref & & & \\
\hline & & Female & 0.05 & 1.05 & $0.74-1.49$ & 0.803 \\
\hline & & Other & 0.86 & 2.37 & $0.63-8.92$ & 0.201 \\
\hline & \multirow{5}{*}{ Ethnicity } & NZ European & 1.71 & 5.50 & $3.04-9.96$ & $<0.001$ \\
\hline & & Maori & 0.63 & 1.88 & $1.06-3.35$ & 0.031 \\
\hline & & Pasifika & -0.19 & 0.83 & $0.38-1.81$ & 0.640 \\
\hline & & Asian & 0.11 & 1.11 & $0.56-2.21$ & 0.761 \\
\hline & & Other & 1.00 & 2.72 & $1.47-5.03$ & 0.001 \\
\hline \multirow{11}{*}{$\begin{array}{l}\text { Prescription drug use vs. } \\
\text { No prescription drug use }\end{array}$} & \multirow{3}{*}{ Age } & 18-24 years & Ref & & & \\
\hline & & 25-34 years & 0.76 & 2.13 & $0.89-5.13$ & 0.091 \\
\hline & & 35 or older & 0.31 & 1.36 & $0.40-4.61$ & 0.617 \\
\hline & \multirow{3}{*}{ Gender } & Male & Ref & & & \\
\hline & & Female & 0.14 & 1.15 & $0.72-1.85$ & 0.558 \\
\hline & & Other & -0.34 & 0.71 & $0.19-2.63$ & 0.609 \\
\hline & \multirow{5}{*}{ Ethnicity } & NZ European & 0.58 & 1.79 & $0.79-4.04$ & 0.161 \\
\hline & & Maori & 0.36 & 1.43 & $0.69-2.97$ & 0.337 \\
\hline & & Pasifika & -0.23 & 0.80 & $0.29-2.21$ & 0.662 \\
\hline & & Asian & -0.44 & 0.65 & $0.25-1.70$ & 0.377 \\
\hline & & Other & 0.09 & 1.09 & $0.47-2.54$ & 0.843 \\
\hline
\end{tabular}

\subsubsection{Ecstasy or MDMA}

The model was significant, $\chi^{2}(\mathrm{df}=9, n=798)=98.925, p<0.001$. Age and ethnicity made a significant contribution to the model (Table 5). Respondents who were aged 25-34 had higher odds than respondents aged 18-24 of having family/whānau or close friend who used ecstasy/MDMA in a harmful way ( $\mathrm{AOR}=2.88,95 \% \mathrm{CI}: 1.53$ to 5.43 ). NZ European ( $\mathrm{AOR}=5.50,95 \% \mathrm{CI}$ : 3.04 to 9.96$)$, Māori ( $\mathrm{AOR}=1.88,95 \% \mathrm{CI}: 1.06$ to 3.35), and Other ( $\mathrm{AOR}=2.72,95 \% \mathrm{CI}: 1.47$ to 5.03 ) had higher odds of having family/whānau member or close friend who used ecstasy/MDMA in a harmful way than non-NZ European, non-Māori, and non-Other, respectively.

\subsubsection{Prescription Drugs}

The overall model was significant, $\chi^{2}(\mathrm{df}=9, n=798)=18.800, p=0.027$, but age, gender, and ethnicity did not make a significant contribution to the model (Table 5). 


\section{Discussion}

The current study adds to the growing literature on AoD use and its potential effects on tertiary students. Further, the study explores new approaches that move the discourse on AoD use beyond an individual user to their close contacts (family and friends). Consistent with previous population surveys [4], this study found that age and ethnicity were significantly associated with having family/whānau member or close friend who had used AoD harmfully. Overall, 36.2\% of respondents had family/whānau member or close friend who had consumed alcohol in a harmful way, and $42.9 \%$ had family/whānau member or close friend who had used at least one drug in a harmful way in the last 12 months.

Although the survey questions and methods (online and paper questionnaires) used in this study were exploratory, they appear sound and the findings are comparable to findings of studies that used 'traditional' approaches (i.e., in-person interviews with people who use AoD or with people in the general population). For example, Māori participants were more likely than non-Māori to report family/whānau member or close friends who consumed alcohol harmfully, and age and ethnicity were significantly associated with participants reporting cannabis and ecstasy or MDMA use among family/whānau members or close friends, consistent with the NZHS [4].

There are considerable differences, however, between the results of the current study and those from the general population. Our results of harmful alcohol consumption (36.2\%) and cannabis use (32.7\%) were substantially higher compared with the 2020/21 estimates from the NZHS, where $19.9 \%$ of adults engaged in hazardous drinking and $15.3 \%$ used cannabis in the past year [4]. The differences between these estimates may be due to a number of reasons. Firstly, the NZHS gathers information directly from individual users of AoD whereas the current study used secondary sources (family/whānau members and close friends of users). Under-reporting of alcohol consumption is common in selfreported population surveys [28,29]. Individual users may under-report use due to fear of stigmatisation, and family members may under-disclose AoD use by their loved ones in one-on-one interviews due to concealed stigma [30], which is associated with chronic sorrow among family members and close friends of people using AoD. Secondly, it is possible that some participants in the current study may have nominated the same people: flatmates, classmates, or workmates may have common close friends and may engage in similar activities, including harmful AoD use.

Another significant finding was that students aged 25-34 years were more likely than those aged 18-24 years to report harmful cannabis use among their family members or close friends, whereas in the general population the prevalence of cannabis use was higher in people aged 18-24 years than 25-34 years (38.2\% vs. 23.4\%). These differences should be investigated further to understand what they mean and to determine the validity of the survey tools 'explored' in the current study. As the AoD use environment continues to evolve, particularly in the face of the COVID-19 pandemic, public health tools must also evolve to address new challenges. Accurate information about AoD use is important for targeted preventative interventions. Data from secondary sources (family, close friends) can help to supplement self-reported data and identify inconsistencies in prevalence estimates from traditional national population surveys.

While we know that there is a high prevalence of harmful AoD use in New Zealand, it appears that many more people are close to someone with harmful AoD use, and they may be exposed to the harmful effects of that person's AoD use: about 36\% reported exposure to harmful alcohol use and $43 \%$ to another drug use in the current study. Previous research reports a wide range of harms, including academic, social, emotional, physical, and financial $[26,31,32]$. In an educational setting, an intoxicated family/whānau member or close friend may contribute to a student's poor grades and satisfaction with university or college experience through interrupted study time and sleep (to look after an intoxicated family member, friend, or flatmate) [26]. In addition, students being impacted by AoD use of family and friends could impact student's financial or other support and/or ongoing family relationships. It could also increase anxiety in students who may worry about 
particular family members or close friends at times such that focus is diverted from studies. All these harms are nevertheless potentially preventable.

Given the possible negative impact of having a family/whānau member with alcohol and other drug misuse, consideration could be given to how students, especially Māori, could be supported to build coping and resilience while engaged in studies. Telephone support could assist students faced with situations they wish to address, while maintaining anonymity. Psychosocial counselling and support groups could also provide support to students needing help to manage situations which prove challenging, especially if such support was available through Telehealth and mobile phone-based options, including text messaging and phone apps.

Limitations of this study include a convenience sample and the relatively low response rate with the risk of selection bias. The low response rate means that information was not available from most of the students of interest and it is unknown how well the sample data represent university students in New Zealand [22]. Secondly, the study questions on AoD use were exploratory and have not been previously validated. Thirdly, data were self-reported, and no attempts were made to check the accuracy of these data. Further, the definition of family/whānau or close friend was not specific and may have resulted in some respondents nominating the same person.

This exploratory study provides new data that suggests potentially significant secondhand effects of harmful AoD use on family/whānau and close friends of people who use AoD in New Zealand. University students are vulnerable to the harmful effects of their own AoD use $[20,26,33]$ and of their loved ones and may require support (on and off-campus) to succeed in their studies. The study also provides preliminary data, using novel approaches, that can be used to compare changes in exposure to harmful AoD use among tertiary students. The approaches described in this study (i.e., obtaining information on AoD use from family/whānau members and close friends of people using AoD) should be tested, validated, and used in future research to supplement information collected from traditional in-person surveys with individual AoD users. This would increase the accuracy of data that inform public discourse, and interventions to address the harmful effects of AoD use.

\section{Conclusions}

Over one-third of respondents reported exposure to family/whānau or close friends in New Zealand who engaged in harmful use of $\mathrm{AoD}$ in the previous twelve months (36.2\% alcohol; $42.9 \%$ another drug), and age and ethnicity were significantly associated with harmful AoD exposures. These results were substantially higher compared with estimates from the general population. The study suggests that data from secondary sources, including family/whanau members and close friends of people using alcohol and other drugs, may be necessary to supplement information from traditional in-person surveys of individual users.

Author Contributions: Conceptualization, P.S.; methodology, P.S., B.W. and M.W.-B.; formal analysis, data curation and writing-original draft preparation, B.W.; writing-review and editing, B.W. and P.S.; project administration, B.W.; funding acquisition, P.S. All authors have read and agreed to the published version of the manuscript.

Funding: This research, and the article processing charge, were funded by Family Drug Support Aotearoa (FDS), grant number FDS-07-2020.

Institutional Review Board Statement: The study was conducted according to the guidelines of the Declaration of Helsinki, and approved by the Human Ethics Committee of the University of Canterbury (HEC 2020/35, 16 July 2020).

Informed Consent Statement: Informed consent was obtained from all subjects involved in the study.

Data Availability Statement: The data are not publicly available due to privacy issues. 
Acknowledgments: We thank the students who took part in this research, and the research assistants who supported data collection. We further acknowledge the contribution of Pat Coope, statistical advisor (retired), College of Education, Health and Human Development, University of Canterbury, New Zealand for her support with data analysis.

Conflicts of Interest: The authors declare no conflict of interest. The funders had no role in the design of the study; in the collection, analyses, or interpretation of data; in the writing of the manuscript, or in the decision to publish the results.

\section{References}

1. ÖZDAL, M.A.; Kirikkaleli, Z. Alcohol, Crime and suicide: Empirical evidence from oecd countries. Yönetim Ekon. Araştırmaları Derg. 2018, 16, 255-263.

2. Degenhardt, L.; Charlson, F.; Ferrari, A.; Santomauro, D.; Erskine, H.; Mantilla-Herrara, A.; Whiteford, H.; Leung, J.; Naghavi, M.; Griswold, M. The global burden of disease attributable to alcohol and drug use in 195 countries and territories, 1990-2016: A systematic analysis for the Global Burden of Disease Study 2016. Lancet Psychiatry 2018, 5, 987-1012. [CrossRef]

3. World Health Organization. Global Status Report on Alcohol and Health 2018; World Health Organization: Geneva, Switerland, 2018.

4. Ministry of Health. New Zealand Health Survey: Annual Data Explorer. Available online: https://minhealthnz.shinyapps.io/nzhealth-survey-2020-21-annual-data-explorer/_W_f0009fb8/\#!/explore-indicators (accessed on 11 December 2021).

5. Peacock, A.; Leung, J.; Larney, S.; Colledge, S.; Hickman, M.; Rehm, J.; Giovino, G.A.; West, R.; Hall, W.; Griffiths, P. Global statistics on alcohol, tobacco and illicit drug use: 2017 status report. Addiction 2018, 113, 1905-1926. [CrossRef]

6. Connor, J.; Kydd, R.; Shield, K.; Rehm, J. The burden of disease and injury attributable to alcohol in New Zealanders under 80 years of age: Marked disparities by ethnicity and sex. Cancer 2015, 2, 3.

7. Ministry of Transport. Drug Driving Testing. August 2020. Available online: http://www.transport.govt.nz/area-of-interest/ safety/drug-driving-testing/ (accessed on 27 November 2020).

8. Poulsen, H.; Moar, R.; Pirie, R. The culpability of drivers killed in New Zealand road crashes and their use of alcohol and other drugs. Accid. Anal. Prev. 2014, 67, 119-128. [CrossRef]

9. Ahlner, J.; Holmgren, A.; Jones, A.W. Prevalence of alcohol and other drugs and the concentrations in blood of drivers killed in road traffic crashes in Sweden. Scand. J. Public Health 2014, 42, 177-183. [CrossRef]

10. Inter-Agency Committee on Drugs. National Drug Policy 2015 to 2020; Ministry of Health: Wellington, New Zealand, 2015; pp. 1-30.

11. Casswell, S.; Harding, J.F.; You, R.Q.; Huckle, T. Alcohol's harm to others: Self reports from a representative sample of New Zealanders. N. Z. Med. J. 2011, 124, 75-84.

12. Casswell, S.; You, R.Q.; Huckle, T. Alcohol's harm to others: Reduced wellbeing and health status for those with heavy drinkers in their lives. Addiction 2011, 106, 1087-1094. [CrossRef]

13. Connor, J.L.; Kypri, K.; Bell, M.L.; Cousins, K. Alcohol involvement in aggression between intimate partners in New Zealand: A national cross-sectional study. BMJ Open 2011, 1, e000065. [CrossRef]

14. Ministry of Health. Alcohol and Other Drug Policy. Available online: https://www.health.govt.nz/our-work/mental-healthand-addiction/addiction/alcohol-and-other-drug-policy (accessed on 13 December 2021).

15. Branstetter, S.A.; Low, S.; Furman, W. The influence of parents and friends on adolescent substance use: A multidimensional approach. J. Subst. Use 2011, 16, 150-160. [CrossRef]

16. Brooks-Russell, A.; Simons-Morton, B.; Haynie, D.; Farhat, T.; Wang, J. Longitudinal relationship between drinking with peers, descriptive norms, and adolescent alcohol use. Prev. Sci. 2014, 15, 497-505. [CrossRef]

17. Australian Bureau of Statistics. National Survey of Mental Health and Wellbeing: Summary of Results, 2007; Australian Bureau of Statistics: Canberra, Australia, 2008.

18. Borsari, B.; Carey, K.B. How the quality of peer relationships influences college alcohol use. Drug Alcohol Rev. 2006, 25, 361-370. [CrossRef] [PubMed]

19. Connor, J.; Psutka, R.; Cousins, K.; Gray, A.; Kypri, K. Risky drinking, risky sex: A national study of New Zealand university students. Alcohol. Clin. Exp. Res. 2013, 37, 1971-1978. [CrossRef] [PubMed]

20. Kypri, K.; Paschall, M.J.; Langley, J.; Baxter, J.; Cashell Smith, M.; Bourdeau, B. Drinking and alcohol—Related harm among New Zealand university students: Findings from a National Web-Based Survey. Alcohol. Clin. Exp. Res. 2009, 33, 307-314. [CrossRef]

21. El Ansari, W.; Sebena, R.; Labeeb, S. Multiple risk factors: Prevalence and correlates of alcohol, tobacco and other drug (ATOD) use among university students in Egypt. J. Subst. Use 2015, 20, 380-388. [CrossRef]

22. Rickwood, D.; George, A.; Parker, R.; Mikhailovich, K. Harmful alcohol use on campus: Impact on young people at university. Youth Stud. Aust. 2011, 30, 34-40.

23. Davoren, M.P.; Demant, J.; Shiely, F.; Perry, I.J. Alcohol consumption among university students in Ireland and the United Kingdom from 2002 to 2014: A systematic review. BMC Public Health 2016, 16, 173. [CrossRef]

24. Hingson, R.W.; Zha, W.; Weitzman, E.R. Magnitude of and trends in alcohol-related mortality and morbidity among US college students ages 18-24, 1998-2005. J. Stud. Alcohol Drugs Suppl. 2009, 12-20. [CrossRef] 
25. White, A.; Hingson, R. The burden of alcohol use: Excessive alcohol consumption and related consequences among college students. Alcohol Res. Curr. Rev. 2013, 35, 201-218.

26. Cabalatungan, S.; McCarthy, B. Second-hand effects of college drinking and educational experiences: Findings from an analysis of pooled cross-sections. Drugs: Educ. Prev. Policy 2015, 22, 463-469.

27. Student Job Search. Who Can Use Us. Available online: https://www.sjs.co.nz/content/students-who-can-use-us (accessed on 25 May 2021).

28. Boniface, S.; Kneale, J.; Shelton, N. Drinking pattern is more strongly associated with under-reporting of alcohol consumption than socio-demographic factors: Evidence from a mixed-methods study. BMC Public Health 2014, 14, 1297. [CrossRef] [PubMed]

29. Nielsen, D.G.; Andersen, K.; Nielsen, A.S.; Juhl, C.; Mellentin, A. Consistency between self-reported alcohol consumption and biological markers among patients with alcohol use disorder-A systematic review. Neurosci. Biobehav. Rev. 2021, 124, 370-385. [CrossRef]

30. Quinn, D.M.; Earnshaw, V.A. Concealable stigmatized identities and psychological well-being. Soc. Personal. Psychol. Compass 2013, 7, 40-51. [CrossRef] [PubMed]

31. Burns, S.; Crawford, G.; Hallett, J.; Jancey, J.; Portsmouth, L.; Hunt, K.; Longo, J. Consequences of low risk and hazardous alcohol consumption among university students in Australia and implications for health promotion interventions. Open J. Prev. Med. 2015, 5, 1-13. [CrossRef]

32. Trockel, M.; Wall, A.; Reis, J. Impact of perceived second-hand consequences related to alcohol use on college students' drinking behavior intent: A test of feasibility. J. Drug Educ. 2002, 32, 179-193. [CrossRef] [PubMed]

33. Arria, A.M.; Caldeira, K.M.; Allen, H.K.; Bugbee, B.A.; Vincent, K.B.; O'Grady, K.E. Prevalence and incidence of drug use among college students: An 8-year longitudinal analysis. Am. J. Drug Alcohol Abus. 2017, 43, 711-718. [CrossRef] 